\title{
Air Pollution and Breast Cancer in Iranian Women Living in Tehran Metropolis
}

\author{
Farima Minaee, Mohammadreza Sohrabi, Mohammad Ali Heidarnia, \\ Alireza Mosavi Jarrahi
}

Community Medicine Department, Medical school, Shahid Beheshti University of Medical Sciences, Tehran, Iran.

\begin{abstract}
Objective: This study aimed to evaluate the possible association between air pollution and breast cancer in women living in polluted urban area. Methods: A frequency (five years age group) matching case-control study was conducted among women living Tehran Metropolis. Ambient carbon dioxide $\left(\mathrm{CO}_{2}\right)$ as an indicator of exposure to air pollution and particulate matter 10 (PM10) as a carcinogen were used as exposure. Concentrations of the two indicators for the residential address of cases and control for the last five years were obtained from office of Tehran Air Quality Control Bureau (TAQB). All subjects were interviewed by phone and information about other risk factors (hormonal, behavioral anthropometric, and socio-economics) were obtained. Multivariate logistic regression model was used to estimate the odds ratios adjusted for confounding variables. $\mathrm{CO}_{2}$ entered into in the model as a continuous variable and PM10 was categorized as PM10 $\leq 1$ VS $1<$ PM10. Results: A total of 300 cases and 270 controls participated in the study. The mean age for cases and controls were 51.93 and 51.45 years, respectively. The distribution of air pollution throughout the study area indicated a large variation from a minimum of zero (no detectable) to a value of $16165.2612 \mu \mathrm{g} / \mathrm{m}^{3}$ for $\mathrm{CO}_{2}$. This figures were 0.03441 to $8.3242 \mu \mathrm{g} / \mathrm{m}^{3}$ for PM10. In average cases tend to live in areas with higher pollution indicators than controls PM10 was (PM10 < $\left.1 \mu \mathrm{g} / \mathrm{m}^{3}=107\right),\left(1<\mathrm{PM} 10<2 \mu \mathrm{g} / \mathrm{m}^{3}=83\right)$ and $\left(\mathrm{PM} 10>2 \mu \mathrm{g} / \mathrm{m}^{3}=97\right)$ for cases and $\left(\mathrm{PM} 10<1 \mu \mathrm{g} / \mathrm{m}^{3}=108\right),\left(1<\mathrm{PM} 10<2 \mu \mathrm{g} / \mathrm{m}^{3}=87\right)$ and $\left(\mathrm{PM} 10>2 \mu \mathrm{g} / \mathrm{m}^{3}=105\right)$ for controls. Also $\mathrm{CO}_{2}$ index was a significant different with control groups as mean was $\left(3943.87 \pm 3.50 \mu \mathrm{g} / \mathrm{m}^{3}\right)$ for controls and $\left(3199.84 \pm 2.72 \mu \mathrm{g} / \mathrm{m}^{3}\right)$ for cases $(\mathrm{P}$-value $=0.03) . \log \mathrm{CO}_{2}$ as general indicator of exposure to air pollution was not observed association with breast cancer $(\mathrm{OR}=1.218$ and $\mathrm{CI} 95 \% 1.000$ to 1.000$)$. subjects in the case and control groups had no significant difference in terms of the level of PM10 index (OR = 1.047 and CI 95\% 1.005 to 7.278). Conclusion: According to the results of this study, risk of breast cancer increases in women with exposure to air pollution, which denotes air pollution as a potential risk factor of breast cancer.
\end{abstract}

Keywords: Breast cancer- air pollution- prevention- etiology- physiopathology

Asian Pac J Cancer Biol, 2 (2), 51-56

\section{Introduction}

Cancer is the third leading cause of death in Iran after coronary artery disease and traffic accidents. Breast cancer is one of the most severe types of cancer [1], as well as the most common cause of cancer deaths in women across the world. Mortality rate associated with breast cancer has been estimated at $25.5 \%$ of all female cancers [2].

Breast cancer is prevalent in different regions of the world; meanwhile, statistics suggest that the prevalence of
Submission Date: 02/14/2017Ａcceptance Date: 05/25/2017

breast cancer has been on the rise in developing countries [3]. In Tehran city (Iran), breast cancer was reported to be the most common cancer type among women, with the crude incidence rate of 22.4 per 100,000 in 1998 [2].

The main risk factors of breast cancer include hereditary traits and genetic mutations, family history, reproductive parameters, age at menarche, pregnancy, length of breastfeeding, and use of contraceptives [4]. Furthermore, environmental factors have been shown to play a pivotal role in the incidence of breast cancer; such

Corresponding Author:

Dr. Alireza Mosavi Jarrahi

Department Community Medicine Department, Medical school, Shahid Beheshti University of Medical Sciences, Tehran, Iran.

Email: rmosavi@yahoo.com 
examples are exposure to environmental pollutants and smoking habits.

Development of industrialization and urbanization has led to the release of life-threatening toxins into the air [5]. According to the literature, risk of breast cancer is significantly higher with increased nitrogen dioxide $\left(\mathrm{NO}_{2}\right)$ concentration of five parts per billion (ppb) [6].

Traffic is a major source of air pollution, which consists of liquid droplets, potential carcinogens, $\mathrm{NO}_{2}$ gas, and other aromatic hydrocarbons. Researchers have proposed a possible association between the level of air pollution and occurrence of breast cancer. Since aromatic hydrocarbons or aromatic compounds are lipophilic, high concentration and accumulation of these compounds in breast tissues could raise the risk of breast cancer in women [7].

Due to the presence of various gases and particles, determining the exact disease-causing agents of air pollution is rather complex. The air pollution caused by motor vehicles is a major environmental hazard across the globe [8]. Exposure to pollutants, such as $\mathrm{NO}_{2}$ particles and ozone, has been shown to be associated with the risk of hospitalization, mortality and various cancers, including lung, breast, prostate, bladder, ovarian, and cervical cancer [9].

According to a study performed in Iran in 2003, mean age of patients diagnosed with breast cancer was lower among Iranian women compared to patients in other countries, and the majority of these women were reported to be residents of areas with significant air pollution levels [2].

Given the high prevalence of breast cancer in our country and lack of similar research evaluating the effect of pollution on the occurrence of breast cancer, this study aimed to investigate the association between air pollution and breast cancer among Iranian women.

\section{Materials and Methods}

This case-control study recruited 300 incidence cases of breast cancer patient leaving in the Tehran metropolis during 2012-2013. Two hundred seventy-five controls matched to cases (frequency matching based on age group). Cases were recruited from registered cases of a Tehran wide advocacy group. Controls were randomly selected from different areas of Tehran city and matched with the from the database of the registrar of the Social Determinants of Health (SDH) research center.

Exposure, In this study, air pollution rates in different regions of Tehran were obtained from the database of Tehran Air Quality Control Company (AQCC) affiliated to Tehran Municipality. Detailed information in this regard was obtained by measuring the latitude and longitude of all the recorded addresses in the air quality map. This map was issued by Tehran Municipality in order to estimate the daily severity of air pollution and its various markers in different regions of Tehran city.

Air pollution indices were compared in the case and control groups. Moreover, demographic characteristics and reproductive health profile of the patients were obtained via telephone interviews by a trained clinical psychologist. As for control subjects, demographic information was collected by a trained midwife. A researcher-made questionnaire was applied to collect the required data, the validity of which was confirmed by five experts at the Department of Social Medicine and Cancer Research Center.

Objectives of the study were explained to the participants, and written informed consent was obtained from all the subjects prior to the study. In addition, the patients were assured of confidentiality terms regarding their medical records and personal information.

Data analysis was performed in SPSS V.23 using univariate and multivariate analysis, and logistic regression model was used for the adjustment of confounding variables, such as age at menarche, age at menopause, and length of breastfeeding. In this study, $\mathrm{P}$ value of less than 0.05 was considered significant.

\section{Results}

In this study, mean age at menarche was $13.4 \pm 1.40$ and $13.14 \pm 1.35$ years in subjects of the case and control groups, respectively; the groups had a significant difference in this regard $(Z=39338.5)(P<0.001)$. Patients in the case group had more variations in the range of the first, second and third quartiles of age at menopause compared to the control group, and no significant difference was observed in the mean age at menopause between the two groups $(\mathrm{Z}=11232.5)(\mathrm{P}=0.15)$.

With respect to marital status, no significant difference was observed between the subjects of the case and control groups $(\mathrm{Z}=42230.5)(\mathrm{P}=0.65)$. However, comparison of the education level was indicative of a significant difference between the study groups $(\mathrm{Z}=38377)(\mathrm{P}=0.01)$, so that the number of illiterate women and women with academic education was higher in the case group compared to the control group.

Evaluation of the pregnancy history of the subjects was indicative of no significant difference between the two groups $(\mathrm{P}=0.68)$. In addition, the mean of gravidity was reported to be two and three in subjects of the case and control groups, respectively. Comparison of gravidity was indicative of a significant difference between the women in the case and control groups $(\mathrm{Z}=30087.5)(\mathrm{P}<0.0005)$.

In this study, $48 \%$ and $50.9 \%$ of the women in the case and control groups had a history of oral contraceptive use, respectively, and no significant difference was observed between the groups in this regard $(\mathrm{P}=0.48)$. Furthermore, there was no significant difference in the duration of oral contraceptive use between the women in the case and control groups $(\mathrm{Z}=40402.5)(\mathrm{P}=0.59)$.

With regard to the length of breastfeeding, our findings showed no significant difference between the case and control groups $(\mathrm{Z}=26242)(\mathrm{P}<0.0005)$, so that the number of women with more than 20 months of breastfeeding was higher in the case group compared to the control group.

According to the information in Diagram 1, evaluation of different levels of the particulate matter (PM10) index revealed no significant difference in the rate of PM10 
Table 1. Mean of Demographic Variables in Case and Control Groups

\begin{tabular}{|c|c|c|c|c|c|}
\hline & Groups & Mean & $\begin{array}{l}\text { Standard } \\
\text { Deviation }\end{array}$ & Z & P-value \\
\hline \multirow{2}{*}{$\begin{array}{l}\text { Age } \\
\text { (year) }\end{array}$} & Case & 51.93 & 9.31 & $41,783.5$ & 0.58 \\
\hline & Control & 51.45 & 9.67 & & \\
\hline \multirow{2}{*}{$\begin{array}{l}\text { Age at } \\
\text { Menarche }\end{array}$} & Case & 13.4 & 1.4 & $39,338.5$ & $<0.001$ \\
\hline & Control & 13.14 & 1.35 & & \\
\hline \multirow{2}{*}{$\begin{array}{l}\text { Age at } \\
\text { Menopause }\end{array}$} & Case & 47.22 & 5.4 & $11,232.5$ & 0.15 \\
\hline & Control & 46.46 & 6.18 & & \\
\hline \multirow{2}{*}{$\begin{array}{l}\text { Height } \\
(\mathrm{cm})\end{array}$} & Case & 160.31 & 6.93 & 41,647 & 0.74 \\
\hline & Control & 160.18 & 5.6 & & \\
\hline \multirow{2}{*}{$\begin{array}{l}\text { Weight } \\
(\mathrm{kg})\end{array}$} & Case & 69.54 & 11.44 & $40,318.5$ & 0.81 \\
\hline & Control & 67.96 & 10.81 & & \\
\hline \multirow{3}{*}{$\begin{array}{l}\text { Body Mass } \\
\text { Index }\end{array}$} & Case & 27.12 & 4.58 & 0.11 & -1.57 \\
\hline & Control & 26.54 & 4.35 & & \\
\hline & Groups & Percent & No & Z & P-value \\
\hline \multirow{6}{*}{$\begin{array}{l}\text { Occupational } \\
\text { Status }\end{array}$} & Case & $76 \%$ & 228 & 28,122 & $<0.001$ \\
\hline & & $19.30 \%$ & 58 & & \\
\hline & & $4.70 \%$ & 14 & & \\
\hline & Control & $43.20 \%$ & 124 & & \\
\hline & & $38 \%$ & 109 & & \\
\hline & & $18.80 \%$ & 54 & & \\
\hline
\end{tabular}

index between the case and control groups $(\mathrm{Z}=42360)$ $(\mathrm{P}=0.721)$. Comparison of the levels of nitrogen dioxide $\left(\mathrm{NO}_{2}\right)$, carbon dioxide $\left(\mathrm{CO}_{2}\right)$, carbon monoxide $(\mathrm{CO})$, sulfur dioxide $\left(\mathrm{SO}_{2}\right)$, and PM10 indices as markers of traffic-related air pollution in the case and control groups is presented in Figure 2.

According to the results of this study, subjects in the case and control groups had no significant difference in terms of the level of $\mathrm{NO}_{2}$ index $(\mathrm{Z}=42765.5)(\mathrm{P}=0.89)$. Moreover, subjects in the case and control groups were homogenous in terms of the changes of the first, second and third quartiles of $\mathrm{NO}_{2}$ index; however, the scatter plot scores were significantly higher in the women of the case group.

In this study, evaluation of the $\mathrm{CO}_{2}$ index was indicative of a significant difference between the case and control groups $(\mathrm{Z}=38692)(\mathrm{P}=0.01)$. In addition,

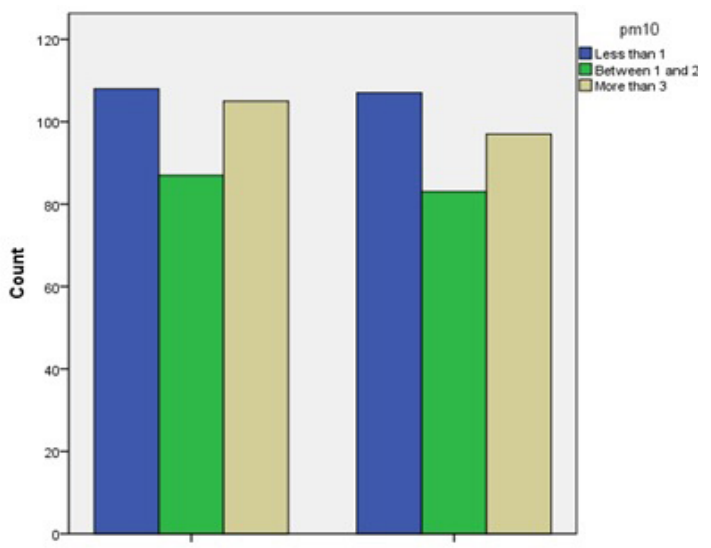

Figure 1. Comparison Of Particulate Matter $\left(\mathrm{PM}_{10}\right)$ Index In Subjects Of Case And Control Groups
Table 2. Logistic Regression Model of Predictive Factors for Breast Cancer in Presence of Independent Variables

\begin{tabular}{llllll}
\hline $\begin{array}{l}\text { Independent } \\
\text { Variables }\end{array}$ & & $\begin{array}{l}\text { Odds } \\
\text { Ratio }\end{array}$ & \multicolumn{2}{l}{ Confidence Interval } & P-value \\
& & & Low & High & \\
\hline Body Mass Index & & 1.023 & 0.958 & 1.093 & 0.492 \\
Age at Menopause & & 1.115 & 1.055 & 1.179 & $<0.0005$ \\
Age at Menarche & & 0.742 & 0.607 & 0.909 & 0.004 \\
Length of & Never & 0.775 & 0.233 & 2.58 & 0.678 \\
Breastfeeding & $1-20$ & 0.091 & 0.049 & 0.168 & $<0.0005$ \\
& Months & & & & \\
Duration of Oral & Never & 0.729 & 0.399 & 1.334 & 0.171 \\
Contraceptive Use & $<$ One & 1.646 & 0.667 & 4.062 & \\
& Year & & & & \\
PM10 Index & $<1$ & 3.187 & 0.981 & 10.353 & 0.12 \\
& $\begin{array}{l}\text { Between } \\
\text { CO }\end{array}$ & 2.705 & 1.005 & 7.278 & \\
\hline
\end{tabular}

changes in the values of the third quartile of $\mathrm{CO}_{2}$ index were more significant in the case group compared to the control group, while the two groups were homogenous in terms of the first and second quartiles of the $\mathrm{CO}_{2}$ index.

Our findings were indicative of no significant difference in the mean of $\mathrm{CO}$ index between the case and control groups $(\mathrm{Z}=39433.5)(\mathrm{P}=0.07)$. However, changes in the $\mathrm{CO}$ index were more divergent in the case group compared to the control group; however, these changes were not considered significant, and the two groups were homogenous in terms of the quartiles of the $\mathrm{CO}$ index. Furthermore, no significant difference was observed in the mean of PM index between the case and control groups $(\mathrm{Z}=41129.5)(\mathrm{P}=0.35)$. Although the study groups were homogenous in terms of the changes of the first, second and third quartiles of the PM index, scores of the scatter plot were significantly higher in the case group.

Evaluation of the $\mathrm{SO}_{2}$ index was indicative of no significant difference between the case and control groups $(\mathrm{Z}=42877.5)(\mathrm{P}=0.93)$. Considering the standard deviation, scores of the scatter plot were significantly high in subjects of both the case and control groups.

Assessment of the relationship between the demographic data of subjects and breast cancer response to chemotherapy is shown in Table 2. Demographic variables in this study included the use of contraceptives, length of

Table 3. Mean of Indicators in Case and Control Groups

\begin{tabular}{lccccc}
\hline & VAR & N & Mean & $\begin{array}{c}\text { Std. } \\
\text { Deviation }\end{array}$ & $\begin{array}{c}\text { Std. Error } \\
\text { Mean }\end{array}$ \\
\hline \multirow{2}{*}{ SUM_NOx } & control & 297 & ators24.938540 & 15.888 & 0.922 \\
& case & 290 & 25.29 & 17.497 & 1.027 \\
SUM_CO2 & control & 297 & $3,222.044$ & $2,727.796$ & 158.282 \\
& case & 290 & $3,946.802$ & $3,529.527$ & 207.261 \\
SUM_SOx & control & 297 & 1.960 & 2.955 & 0.171 \\
& case & 290 & 1.841 & 2.848 & 0.167 \\
SUM_PM10 & control & 297 & 1.702 & 1.337 & 0.077 \\
& case & 290 & 1.866 & 1.585 & 0.093 \\
Logc02 & control & 296 & 3.322 & 0.483 & 0.0281 \\
& case & 287 & 3.380 & 0.579 & 0.034 \\
\hline
\end{tabular}




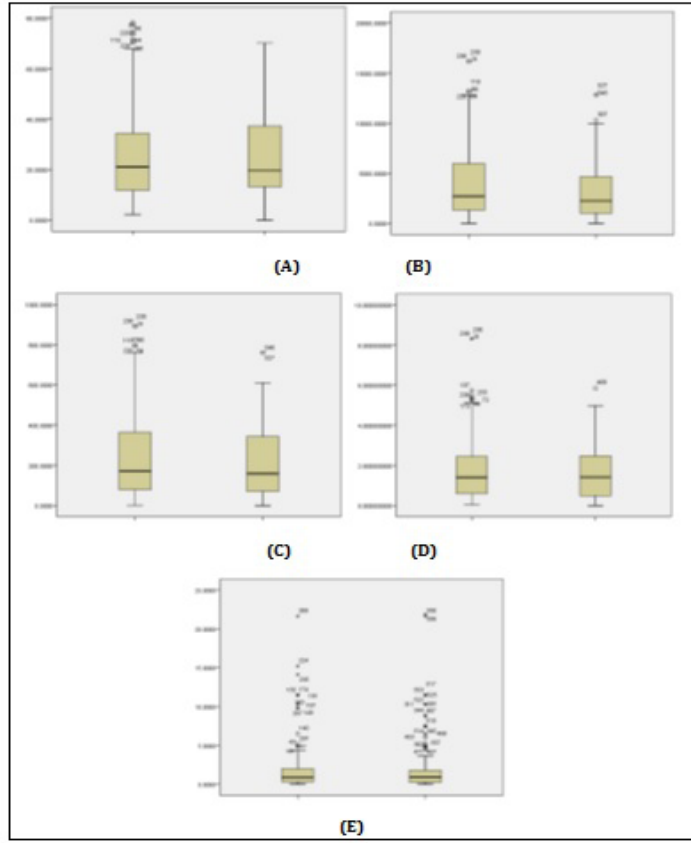

Figure 2. Comparison of $\mathrm{NO}_{2}(\mathrm{~A}), \mathrm{CO}(\mathrm{B}), \mathrm{CO}(\mathrm{C}), \mathrm{PM}$ (D), and $\mathrm{SO}_{2}(\mathrm{E})$ in Case and Control Groups

breastfeeding and air pollution indices. According to the goodness of fit index (GFI) (Nagelkerke's R2), 48\% of the changes in the response variable were explained by the independent variables (i.e., demographic data).

Results of the logistic regression model to identify the predictive factors for breast cancer in the presence of independent variables are presented in Table 2.

According to the information in Table 2, age at menopause was significantly associated with the incidence of breast cancer $(\mathrm{P}<0.001)$, so that the risk of breast cancer was 1.11 times higher per each year of increased age at menopause. Moreover, a significant correlation was observed between age at menarche and incidence of breast cancer $(\mathrm{P}=0.004)$, so that the risk of breast cancer was 1.35 times higher per each year of increased age at menarche.

Findings of this study were indicative of a significant association between the length of breastfeeding and incidence of breast cancer $(\mathrm{P}<0.001)$, so that the risk of breast cancer was 0.09 times higher in women with breastfeeding length of 1-20 months compared to those with breastfeeding length of more than 20 months. Furthermore, $\mathrm{CO}_{2}$ index had a significant correlation with the incidence of breast cancer $(\mathrm{P}=0.01)$, so that the risk of breast cancer was 1.0001 times higher per a one-unit increase in the $\mathrm{CO}_{2}$ index.

Our findings were indicative of no significant relationship between the PM10 index and incidence of breast cancer $(\mathrm{P}=0.12)$. However, a significant association was observed between the level of PM10 index and incidence of breast cancer, so that the risk of breast cancer was 3.1 times higher in women who were exposed to PM10 air pollution index of $<1$ compared to those exposed to $\mathrm{PM} 10$ air pollution index of $>2(\mathrm{P}=0.05)$. In addition, risk of breast cancer was 2.7 times higher in women exposed to PM10 air pollution index of 1-2 compared to those exposed to PM10 air pollution index of $>2$.
Table 4. Odds Ratio of Main Indicators Adjusted for Parity

\begin{tabular}{lcc}
\hline Variable & p- value & Odds ratio \\
\hline SUM_Nox & 0.6 & 1.003 \\
SUM_PM10 & 0.651 & 1.047 \\
Log CO & 0.226 & 1.218 \\
\hline
\end{tabular}

\section{Discussion}

According to the results of the present study, age at menopause was associated with the incidence of breast cancer, while similar studies have reported no significant relationship between these variables $[2,10]$. Furthermore, our findings indicated that the mean age at menarche was significantly lower in the women of the experimental (case) group compared to control subjects, while the two study groups were homogenous in terms of age at menopause.

In the present study, age at menarche was significantly associated with the incidence of breast cancer, so that the odds ratio of breast cancer reduced by 0.74 per each year of increased age at menarche. According to a study by Huo et al., age at menarche is lower in the women who live in areas with high rates of environmental pollution [5]. On the other hand, findings of Nie et al. showed that high exposure to traffic emissions during early menarche could increase the risk of premenopausal breast cancer. Therefore, it was concluded that early-life exposure to air pollutants significantly affects the risk of breast cancer [1].

Findings of the current research were indicative of no association between the incidence of breast cancer and body mass index (BMI). In this regard, the results obtained by Huang et al. showed that the incidence rate of breast cancer was lower before menopause in subjects with higher BMI. Moreover, higher BMI at the age of 18 years was found to be associated with lower incidence of breast cancer before and after menopause. On the other hand, no correlation was reported between weight gain after the age of 18 years and incidence of breast cancer before menopause, while weight gain after the age of 18 years was found to be associated with the incidence of breast cancer after menopause [8]. In another research by Roohparvarzade, BMI of $>30 \mathrm{~kg} / \mathrm{m}^{2}$ was considered as a major risk factor of breast cancer [2]. In this regard, the results of another study indicated that BMI has a reverse correlation with the pre-menopause period and a direct association with the post-menopause period. Therefore, it was suggested that proper weight control in women could remarkably reduce the risk of breast cancer [11].

According to the findings of the present study, incidence of breast cancer was significantly correlated with the length of breastfeeding, so that the risk of breast cancer was higher in women with breastfeeding length of 1-20 months compared to those with breastfeeding length of more than 20 months. This finding is in congruence with the results of previous studies in this regard [2].

In the current study, the case and control groups had a significant difference in terms of the $\mathrm{CO}_{2}$ index, so that the risk of breast cancer was 1.0001 times higher per a 
one-unit increase in the $\mathrm{CO}_{2}$ index. Although no significant association was observed between the PM10 index and incidence of breast cancer, the relationship between the levels of PM10 index and breast cancer was significant. According to the findings of Huo et al., long-term exposure to air pollution (e.g., PM10) could be an external factor raising the risk of breast cancer through acting as a xenoestrogen [5].

Consistent with the results of the present study, Nie et al., reported that the risk of premenopausal breast cancer at the time of menarche increases due to high exposure to traffic emissions. Furthermore, frequent exposure to traffic emissions during the first menarche was associated with higher risk of postmenopausal breast cancer, which confirms that early exposure to traffic emissions is a major risk factor for breast cancer [1].

According to another study by Crouse et al., the adjusted odds ratio was 1.31 per $5 \mathrm{ppb}$ unit increase of $\mathrm{NO}_{2}$. In addition, the researchers proposed that the risk of breast cancer was $25 \%$ higher per 5 ppb increase of $\mathrm{NO}_{2}$ exposure; however, this effect was reported to be variable at different periods. According to the other findings of the mentioned study, incidence of postmenopausal breast cancer and exposure to ambient concentrations of $\mathrm{NO}_{2}$ were directly correlated [6].

In another study by Chen et al., a significant correlation was reported between the geographic distribution of motor vehicles in 1970 and incidence rate of breast cancer during 1980-1995 [4]. In this regard, Hung et al. reported that the mortality rate associated with ovarian cancer was higher in women living in regions with higher concentrations of PM2.5 and polycyclic aromatic hydrocarbons (PAHs) compared to those living in regions with the lowest levels of PM2.5 [8]. As is known, breast cancer and ovarian cancer are directly correlated. In this regard, the results obtained by Bonner et al. showed that the risk of postmenopausal breast cancer increased due to the early exposure of subjects to high concentrations of PAHs [12].

Findings of the present study were inconsistent with the results obtained by Reding et al., which denoted no association between the risk of breast cancer and exposure to concentrations of PM2.5 and PM10. However, based on the breast cancer subtypes defined by patterns of estrogen receptor (ER) and progesterone receptor (PR), occurrence of breast cancer was associated with $\mathrm{NO}_{2}$ levels, which could differentially affect $\mathrm{ER}(+) / \mathrm{PR}(+)$ breast cancer [13].

In a systematic review, Kariminia et al. evaluated the effect of $\mathrm{NO}_{2}$ exposure on the incidence of breast cancer and reported a weak association between exposure to $\mathrm{NO}_{2}$ in ambient air and incidence of breast cancer at the individual level, while a significant association was observed at the aggregate level [14]. In another study by Fazzo et al., breast cancer was reported to be affected by exposure to priority index contaminants in ambient air [15].

According to the results of another research, genespecific methylation of RAR $\beta$ might interact with PAHDNA adducts increasing the risk of hormone receptorpositive breast cancer [16]. Furthermore, the findings of Parikh et al. suggested that PAH and PM2.5 emissions are a major contributing factor for the occurrence of breast cancer. Therefore, it could be concluded that ambient air pollution remarkably affects the incidence of breast cancer [17].

Evaluation of the relationship between air pollution and breast cancer is essential to the improvement of the quality of life and health of women. As such, prompt establishment or modification of health strategies in this regard is of paramount importance. It is recommended that future studies assess the role of exposure to air pollutants in the etiology of breast cancer. Moreover, further investigation is required as to confirm whether air pollution components of traffic emissions are associated with other risk factors of breast cancer.

\section{Strengths and limitations}

One of the strengths of this study was the selection of subjects from two separate centers with considerable diversity. In addition, subjects in the control group were selected from various regions of Tehran city; however, number of subjects in the case and control groups was low due to the limited cooperation of authorities.

One of the limitations of this study was failure to measure the exposure of subjects to air pollutants at home and work separately since we were not able to distinguish between the working hours at home and in the office. In addition, some of the data were obtained via phone interviews, which might have undermined data reliability. It is also noteworthy that this was a pilot study, and further research is required as to investigate the role of exposure to air pollutants in the etiology of breast cancer development.

According to the results of this study, risk of breast cancer is relatively high in women who are exposed to air pollution, which denotes the potential of air pollution in raising the risk of breast cancer. Findings of this study offer a new insight into the association between air pollution and breast cancer. In conclusion, it is recommended that proper measurement tools be applied to identify the quality of motor vehicle pollution in order to reduce $\mathrm{CO}_{2}$ levels as a marker of traffic-related air pollution involved in the development of breast cancer.

\section{Acknowledgments}

Hereby, we extend our gratitude to AQCC (affiliated to Tehran Municipality), Mr. Mohsen Roshani and Mr. Hamian for their cooperation and guidance in this study. We would also like to thank the authorities of Sepas Cancer Support Institute, Ms. Yaraee and Ms. Sobhani for assisting us in this research project.

\section{References}

1. Nie J, Beyea J, Bonner MR, Han D, Vena JE, Rogerson P, et al. Exposure to traffic emissions throughout life and risk of breast cancer: the Western New York Exposures and Breast Cancer (WEB) study. Cancer Causes Control. 2007;18(9):947-55.

2. Roohparvarzade N. Prevalence of risk factors for breast cancer in women (20 to 69 Years old) in Isfahan 2012-2013. Iranian 
Journal of Breast Disease. 2014;7(1):52-61.

3. Harirchi I, Karbakhsh M, Kashefi A, Momtahen AJ. Breast cancer in Iran: results of a multi-center study. Asian pacific journal of cancer prevention. 2004;5(1):24-7.

4. Chen F, Bina WF. Correlation of white female breast cancer incidence trends with nitrogen dioxide emission levels and motor vehicle density patterns. Breast cancer research and treatment. 2012;132(1):327-33.

5. Huo Q, Zhang N, Wang X, Jiang L, Ma T, Yang Q. Effects of ambient particulate matter on human breast cancer: is xenogenesis responsible? PloS one. 2013;8(10):e76609.

6. Crouse DL, Goldberg MS, Ross NA, Chen H, Labrèche F. Postmenopausal breast cancer is associated with exposure to traffic-related air pollution in Montreal, Canada: a case-control study. Environmental health perspectives. 2010;118(11):1578.

7. Morris J, Seifter E. The role of aromatic hydrocarbons in the genesis of breast cancer. Medical hypotheses. 1992;38(3):177-84.

8. Hung L-J, Chan T-F, Wu C-H, Chiu H-F, Yang C-Y. Traffic air pollution and risk of death from ovarian cancer in Taiwan: Fine particulate matter (PM2. 5) as a proxy marker. Journal of Toxicology and Environmental Health, Part A. 2012;75(3):174-82.

9. Al-Ahmadi K, Al-Zahrani A. NO2 and Cancer Incidence in Saudi Arabia. International Journal of Environmental Research and Public Health. 2013;10(11):5844-62.

10. Trentham-Dietz A, Sprague BL, Hampton JM, Miglioretti DL, Nelson HD, Titus LJ, et al. Modification of breast cancer risk according to age and menopausal status: a combined analysis of five population-based case-control studies. Breast cancer research and treatment. 2014;145(1):165-75.

11. Van den Brandt PA, Spiegelman D, Yaun S-S, Adami H-O, Beeson L, Folsom AR, et al. Pooled analysis of prospective cohort studies on height, weight, and breast cancer risk. American journal of epidemiology. 2000;152(6):514-27.

12. Bonner MR, Han D, Nie J, Rogerson P, Vena JE, Muti P, et al. Breast cancer risk and exposure in early life to polycyclic aromatic hydrocarbons using total suspended particulates as a proxy measure. Cancer Epidemiology Biomarkers \& Prevention. 2005;14(1):53-60.

13. Reding KW, Young MT, Szpiro AA, Han CJ, DeRoo LA, Weinberg C, et al. Breast Cancer Risk in Relation to Ambient Air Pollution Exposure at Residences in the Sister Study Cohort. Cancer Epidemiol Biomarkers Prev. 2015;24(12):1907-9.

14. Keramatinia A, Hassanipour S, Nazarzadeh M, Wurtz M, Monfared AB, Khayyamzadeh M, et al. Correlation Between Nitrogen Dioxide as an Air Pollution Indicator and Breast Cancer: a Systematic Review and Meta-Analysis. Asian Pacific journal of cancer prevention: APJCP. 2015;17(1):419-24.

15. Fazzo L, Carere M, Tisano F, Bruno C, Cernigliaro A, Cicero MR, et al. Cancer incidence in Priolo, Sicily: a spatial approach for estimation of industrial air pollution impact. Geospatial Health. 2016;11(1).

16. White AJ, Chen J, McCullough LE, Xu X, Cho YH, Teitelbaum SL, et al. Polycyclic aromatic hydrocarbon (PAH)-DNA adducts and breast cancer: modification by gene promoter methylation in a population-based study. Cancer Causes Control. 2015;26(12):1791-802.

17. Parikh PV, Wei Y. PAHs and PM2. 5 emissions and female breast cancer incidence in metro Atlanta and rural Georgia. International Journal of Environmental Health Research. 2016:1-9.
This work is licensed under a Creative Commons AttributionNon Commercial 4.0 International License. 